\title{
Reloj de archivos
}

\author{
Juan Manuel Herrera
}

0 i uno se asoma al portal de archivos de la UNEsCO, ${ }^{1}$ donde se da noticia y acceso a más de 7500 sitios relacionados con archivos y con recursos documentales e informativos en el mundo, por igual número de instituciones públicas y privadas, incluyendo universidades e institutos de investigación, así como referencias a programas y políticas en torno a la administración de documentos y al control normalizado del patrimonio histórico documental, uno puede hacerse una idea del arco de tiempo y los cambios que han ocurrido en el último cuarto de siglo en el mundo de la información, la transparencia y el conocimiento que se desprenden de la documentación pública.

El usuario puede beneficiarse con la consulta de tres portales más, relacionados con otros tantos temas centrales de la educación, el conocimiento y la transparencia: las bibliotecas, el software libre de derechos y el Observatorio de la Sociedad de la Información. La página electrónica incluye información de instituciones de gobierno, académicas, culturales, de industria y trabajo, parlamentarias, recursos

${ }^{1}$ Véase <http://www.unesco.org/webworld/portal_archives>. de fuentes primarias - documentos, exposiciones, instrumentos de consulta, proyectos-, publicaciones, legislación, normatividad, educación y capacitación, informes y programas de preservación y conservación, noticias de comunidades y asociaciones de profesionales, conferencias, convocatorias e informes relativos a la cooperación internacional. En fin, novedades del universo de los archivos en África, el mundo árabe, Asia-Pacífico, Europa, Latinoamérica y el Caribe y Norteamérica.

El portal de la UNESCO da cuenta del estado del arte en materia de archivos en el mundo. Es una manera, acaso la más eficaz, de acceder a los acervos, a los documentos técnicos y a los recursos útiles para alcanzar las mejores prácticas en este ámbito. Por añadidura, es el vínculo organizado más ambicioso para documentar vastos campos de la historia del mundo, a través de la perspectiva nacional e institucional que cada sitio particular ofrece. Es posible tener a la vista los mejores ejemplos y evaluar otras experiencias para tener a la mano abundante información técnica, de normas y procedimientos; innumerables posibilidades para la comprensión de los temas asociados con el estudio y el conocimiento de

\section{Archives Clock}

Juan Manuel Herrera: Biblioteca “Miguel Lerdo de Tejada”, Distrito Federal, México manuel_herrera@hacienda.gob.mx

Desacatos, núm. 39, mayo-agosto 2012, pp. 187-192 
un territorio histórico, e inagotables recursos informativos de todo el planeta, conservados en instituciones de archivo. Dicho sitio, en consecuencia, debe ser tomado en cuenta en el diseño de políticas de organización y recuperación de información relevante para documentar estudios con una perspectiva histórica. Habrá que imaginar una estructura informativa que despierte el interés por la historia y el presente de la documentación en la administración pública. Sirve por igual, como podrá apreciar de inmediato quien se asome a sus enlaces, como modelo múltiple para la coordinación interinstitucional de las tareas en curso o por realizar, así como para la mejor definición de las prioridades de cada institución. Es, en suma, una herramienta esencial y, a un tiempo, una tautología que suena a Niklas Luhman: el manejo de la información exige el manejo de la información.

Es también una suerte de luz de contraste, pues permite subrayar el cambio radical que los archivos de nuestro país, y en general del mundo entero, han templo". Nos esperaba Ana Laura Delgado para conducir la visita, programada para realizarse en $45 \mathrm{mi}$ nutos — trabajé ahí durante 15 años-. Trabajar en el centro de la ciudad - lo sigo haciendo, pues la Biblioteca "Miguel Lerdo de Tejada", que tengo el honor de dirigir, ocupa el antiguo oratorio de San Felipe Neri- y trabajar en el AGN están en mi glosario personal como sinónimo de felicidad.

Durante estos años he colaborado en numerosos proyectos de archivos vinculados a los tres poderes y en los tres niveles de gobierno, con archivos públicos y privados, con instituciones civiles y eclesiásticas. De tal suerte que tengo, sin vanagloria, diríamos una perspectiva que permite observar la evolución en estos años como un horizonte abierto, no siempre luminoso. He considerado que puede ser útil glosar algunos ejemplos que permitan situar mi experiencia en los archivos durante estos años y, pese al abuso del anecdotario personal, ofrecer un panorama de la experiencia archivística en México a partir del trazo de algunas viñetas propias del mundo de los archivos.

Hoy en día es posible encontrar instituciones con proyectos ambiciosos, con recursos estables y con una perspectiva clara de trabajo. Los acervos en numerosas instituciones, sin embargo, continúan teniendo un estatuto desigual, y se les enfrenta mediante una respuesta insuficiente ante la compleja realidad, las necesidades crecientes y los recursos limitados, realidad a cuyo estudio y comprensión invitó el Congreso Internacional de Archivos, que tuvo lugar en Bonn en la década de 1980. Todavía es común que se atiendan las demandas de cada institución como un asunto acumulativo y secuencial, y se resuelven o se intentan resolver problemas concretos.

Hay muchos ejemplos de protección de archivos en México. Uno de ellos es el del Centro Coordinador Tzeltal-Tzotzil, pues forma parte de un esfuerzo más amplio por rescatar, organizar y difundir acervos de interés en el estado de Chiapas. Justus Fenner, destacadamente, ha participado desde hace muchos años en los trabajos de ordenación de archivos municipales, algunos de los cuales han sido rescatados, sin eufemismo, de la basura. En Chiapas, durante 
muchos años los esfuerzos de gente como Andrés Aubry, Carlos Román y desde luego Justus Fenner se han aproximado a la protección del patrimonio como un tema central de interés público.

Como parte del gobierno federal, el ejemplo del Archivo de Migración es muy interesante. Tuve ocasión de conocerlo en circunstancias muy adversas: después de los sismos de 1985. Me tocó en suerte rescatar los registros de inmigrantes que han servido para numerosas investigaciones y todavía está por explorarse un número importante de registros - decenas de miles de fichas en el AGN-. Pero este acervo es sólo una parte del archivo, por lo que el reporte es bueno, ya que hace un balance de la situación, importancia y perspectivas de este valioso acervo -medio millón de expedientes-, además de que supone una agenda de investigación sugerente. Es una buena contribución, sin duda alguna.

Debemos preguntarnos, sin embargo, ¿cómo empezó todo? El nombre clave en este breve repaso es el de la doctora Alejandra Moreno Toscano, quien al llegar a la dirección del AGN modificó sustancialmente no sólo esa institución, puesto que encabezó la organización de archivos en todo el país. Estamos en 1977. No es casual que destaque la experiencia del AGN en la época de Moreno Toscano, pues fue -estoy seguro- el más imaginativo y logrado proyecto para los archivos históricos de México y ejemplo para otras instituciones. El proyecto de la doctora Alejandra Moreno Toscano está ampliamente documentado: el informe que presentó al momento de la inauguración de las instalaciones del AGN en Lecumberri es elocuente. En 1977, la institución estaba en una situación muy precaria. Durante décadas la documentación no había modificado su estatuto frente a la administración pública, frente a la ciudadanía ni frente a los investigadores interesados en la historia de México. Esta circunstancia no quita mérito alguno a los trabajos realizados en la institución entre los años de la comisión reorganizadora y la época de don Ignacio Rubio Mañé. Es decir, seis décadas del siglo xx. Lo que hizo Moreno Toscano, y se dice rápido, fue una vasta convocatoria para modificar dicho estatuto. En primer lugar logró que el proyecto interesara al propio presidente José López Portillo y a los secretarios de Gobernación que apoyaron sus iniciativas, Jesús Reyes Heroles y Enrique Olivares Santana, que fueron incondicionales participantes de ese proyecto. Frente a la comunidad académica, se unieron esfuerzos y numerosos participantes llegaron acaso también por unos minutos. El gobierno federal fomentó la colaboración con estados y municipios para la realización del Registro Nacional de Archivos y para el rescate de archivos en todo el país - civiles y eclesiásticos- con la doctora Stella González a la cabeza. Se trabajaron acervos - casi $1000 \mathrm{~m}^{3}$ de documentación-que se encontraban hacinados en la Casa Amarilla y en sitios inadecuados. Se inició la remodelación del $\mathrm{Pa}$ lacio de Lecumberri y se preparó simultáneamente una mudanza compleja que resultó ejemplar. Por muchos motivos, los trabajos de organización del acervo permitieron - obligaron a- el diseño de un sistema nacional de archivos. Es cierto que esta idea estaba presente en organizaciones internacionales, pero lo es también que México iba a la vanguardia. De tal suerte que se trabajó casi siguiendo el guión que Bruno Delmas establecería como principio metodológico de todo sistema nacional de archivos. Las tareas del AGN se vincularon a todos y cada uno de los aspectos documentales, organizativos, legales y funcionales. Se estableció una red, se capacitó a mucha gente, se propició que una serie de propuestas fueran viables para el rescate de acervos en el gobierno federal, en los estados, en los municipios, aun en archivos privados.

El estado de Jalisco fue pionero en los trabajos de organización de archivos. Resultó favorable, en la época de la doctora Alejandra Moreno Toscano, la presencia de Helen Ladrón de Guevara, así como la de la doctora Carmen Castañeda, junto con un equipo de gente muy comprometida con la conservación de los acervos en Jalisco. Conocí a Carmen Castañeda en la época en la que Alejandra Moreno Toscano era la directora del AGN, años en los que la memoria documental de México fue objeto de una gran atención 
pública: se trabajó el acervo olvidado del propio AGN, dio inicio una vasta campaña para organizar los archivos municipales y estatales en toda la república y los archivos de la administración pública federal fueron dotados de nuevos recursos. Fue una verdadera revolución atenta a la conservación del patrimonio documental y, a un tiempo, a su utilización para la administración pública. Numerosas fuentes dieron lugar a una renovación de los temas de estudio, que propició una nueva etapa en la discusión académica con perspectiva histórica. Hace 30 años, Alejandra, Carmen e innumerables representantes de archivos de todo el país partieron de un diagnóstico nacional:

- No se cuenta con una adecuada legislación referente a la administración de documentos que prevenga y evite la destrucción, pérdida, deterioro y robo de los documentos oficiales e históricos.

- Los archivos administrativos frecuentemente no la toma de decisiones.

- La mayoría de las instituciones del gobierno federal y de los estados y municipios no cuentan con archivos históricos.

- Existe un gran número de archivos sin control dentro de las instituciones.

- Los espacios y equipos no reúnen en la mayoría de los casos mínimos requisitos de funcionalidad.

- La administración no ha creado procedimientos que garanticen la concentración de documentos con valor histórico.

- No hay un flujo ordenado de información conforme a un ciclo.

- El personal encargado de las tareas de archivo en general no cubre los requerimientos mínimos para ocupar el puesto, dado que es una práctica común enviar a las unidades de archivo a personal descalificado.

En la Primera Reunión Nacional de Archivos:

- Se denunció el estado lamentable en que se encontraban la mayor parte de los archivos.

- Se manifestó la necesidad imperiosa de una reforma administrativa en los sistemas de archivo de la administración pública y la necesidad de que se promulgara una ley sobre administración de documentos.

- Se reclamó el reconocimiento del valor profesional de la actividad archivística y se reconoció la urgencia de promover la capacitación en todos los niveles.

- Se solicitó a los gobiernos respectivos la creación y desarrollo de archivos históricos en todos los estados de la república.

- Se estimó imperiosa la formación de un comité nacional permanente de archivos administrativos e históricos coordinado por el Archivo General de la Nación.

- Se consideró el diseño e implantación de un sistema red tipo para estados y municipios.

- Se planteó como indispensable la integración de un Sistema Nacional de Archivos.

Como puede verse, todo o casi todo estaba por hacerse $y$, al igual que en otros países, había muchos escépticos respecto de la viabilidad de un proyecto tan ambicioso. Mi lectura personal acerca de esta primera etapa es que hubo una afortunada coincidencia entre dos líneas paralelas de trabajo que, acumuladas, $y$ en un entorno favorable, lograron despertar gracias al talento de Alejandra, y sobre todo con un rumbo bien definido. Se aprovechó la experiencia acumulada durante más de diez años que una oficina de la Presidencia de la República, la Coordinación de Estudios, tenía tratando de mejorar específicamente los archivos administrativos del gobierno federal. Por su parte, la comunidad académica en el país reclamaba insistentemente mejores condiciones para el patrimonio documental, que en 
las primeras décadas del siglo había sufrido daños considerables y una gran dispersión. La disponibilidad de los recursos archivísticos adolecía de graves limitaciones: piensen en las llamadas de don Daniel Cosío Villegas a la Historia Moderna de México para recordar esas limitaciones.

Se ha dicho que el Sistema Nacional de Archivos "se creó como una respuesta a los graves y complejos problemas de los servicios archivísticos nacionales, concibiéndose como una estrategia permanente de coordinación". También es cierto que el primer diseño del sistema amplificó, permítaseme la expresión, la respuesta ante los problemas graves y complejos que vivía el propio AGN. Fue, digámoslo así, una manera radical de observar un problema de dimensión nacional a través de los problemas que enfrentaba el máximo archivo del país, de modo que se cayó en la cuenta de los rezagos que vivía la comunidad entera de archivos y archivistas. En suma, el AGN era la prueba más elocuente de que se había tocado fondo y que no podía esperarse más para modificar la situación. Se tuvo el talento necesario para reunir voluntades e ideas para transformar su realidad y, por extensión, iniciar o continuar el cambio en la realidad del conjunto de archivos del país. Se atacaron distintos frentes, no siempre con el equilibrio, la intensidad y éxito que todos hubiéramos deseado, pero se hizo con la energía social suficiente para avanzar lenta pero firmemente.

Tras diez años de trabajar en el AGN, entré en contacto con la Suprema Corte de Justicia de la Nación $(\mathrm{scJN})$, en donde me tocó en suerte diseñar las tareas iniciales para la constitución de un sistema, hoy en pleno funcionamiento. Digo en suerte, propiamente, pues el entonces presidente de la SCJN, el ministro Ulises Schmill Ordóñez, solicitó al AGN una opinión acerca de la conservación de los acervos, toda vez que el pleno de ministros había aprobado una resolución en torno a la guarda y depuración de los archivos judiciales. Leonor Ortiz Monasterio, quien era directora del AGN, me encargó el estudio y tres meses después entregué un diagnóstico con recomendaciones al ministro Schmill y a quien entonces fuera su coordinador de asesores, el doctor José Ramón Cosío. Como no estaba familiarizado con la estructura del Poder Judicial Federal —y no está de más insistir en la importancia del conocimiento de las instituciones para el trabajo archivístico-, decidí concentrarme en el análisis de una sola célula de ese complejo universo jurisdiccional: el Juzgado Tercero de Distrito en Materia Administrativa. En ese momento yo era, como la mayor parte de los mexicanos, ignorante de la estructura del Poder Judicial. Logré establecer una propuesta integral para la organización de los acervos y llegamos a la conclusión de que sólo de esa manera, es decir, a través del análisis puntual — no de todo el Poder Judicial — de una sola de sus estructuras era posible entender lo que podría hacerse y, de inmediato, ponerlo en práctica. El ministro Schmill recibió con entusiasmo la propuesta y el pleno de ministros aprobó una serie de apoyos para los trabajos iniciales. Más tarde fue necesario trasladar todos los acervos que se encontraban en el edificio de Avenida Universidad a las nuevas instalaciones de San Lázaro, y esta mudanza también simbolizó - como en el caso del AGN - una transformación institucional profunda. Todo el apoyo del pleno de ministros y del presidente de la SCJN resultaron de principal importancia. A partir de ese momento fue posible acercarse a los distritos y a cada juzgado. Como las circunstancias no daban para formar ni contratar a un equipo entrenado y suficiente, solicité apoyo al ministro Schmill para que de cada uno de los juzgados civiles, administrativos y penales se designara a una sola persona, quien fuera, para conjuntar una suerte de brigadas de trabajo. De la noche a la mañana tenía un equipo de decenas de personas inquietas porque no sabían a ciencia cierta de qué se trataba la cosa. Resulta muy alentador comprobar que en periodos sucesivos la SCJN ha refrendado el apoyo a sus programas de archivo, es decir, el Poder Judicial se ha beneficiado de un respaldo continuo desde la época del presidente Ulises Schmill a la fecha. Esta continuidad de los proyectos es sustancial. Otro aspecto central en el caso de los archivos judiciales es que la documentación 
- a diferencia de lo que ocurre en el Ejecutivo- es homogénea, por tratarse de negocios que tienen lugar en los distintos órganos jurisdiccionales. Ésta es una ventaja inestimable y es posible y deseable encontrar apoyo y estímulo en los programas que en la federación y en otros estados se han realizado en la materia. No es exagerado afirmar que hoy en día los archivos mejor instalados, con ideas más claras acerca de su funcionamiento y con resultados más homogéneos en beneficio de la sociedad en su conjunto son los archivos judiciales. Puede sonar a paradoja, pero es afortunado que esto ocurra en el entorno actual.

Finalmente, coordiné junto con Victoria San Vicente dos ambiciosos proyectos de descripción, que en buena medida son tareas de organización de mucho trabajo acumulado por generaciones de archivistas: primero en el propio AGN y después en el Archivo Histórico de la Ciudad de México (АHCM). La descripción de acervos acumulados es una de las tareas más importantes para la difusión de la riqueza documental y para propiciar el estudio de las fuentes para la historia. Al reunir, bajo el principio de un registro central, todos los instrumentos de consulta fue posible observar el trabajo de 200 años, es decir, el trabajo de generaciones de personas que día con día habían desarrollado - con criterios heterogéneos, cambiantes, contrapuestos, redundantes- instrumentos de consulta de todo tipo: inventarios, guías, catálogos, listas y toda clase de repertorios. No era la primera guía en la institución, pero acaso era la primera en cuyo principio metodológico se buscaba participar de reglas internacionales.

El Centro de Investigaciones y Estudios Superiores en Antropología Social (CIESAS) ha participado en proyectos decisivos para la conservación de algunos acervos de primera importancia en el país: el Archivo Agrario y el Archivo Histórico del Agua, los dos surgidos de iniciativas de la doctora Teresa Rojas Rabiela, a la sazón directora general del cIESAS. Estos archivos sumaron en pocos años un inmenso volumen de acervos bien ordenados, bien descritos $y$ con un obvio beneficio institucional que ha abierto a la consulta para la investigación académica un cúmulo insospechado de documentación valiosa $y$, desde luego, ha hecho visible un recurso fundamental para la actividad pública en la administración en la Secretaría de la Reforma Agraria y en la Comisión Nacional del Agua.

Las experiencias de estos 25 años en materia de archivos en México deberán ser consideradas fundamentalmente hoy, que se diseña un nuevo marco jurídico, al más alto nivel, para dotar a los archivos mexicanos de mejores recursos, para fortalecer al AGN como la institución central y como condición para consolidar los esfuerzos en materia de transparencia. 